\section{(2) OPEN ACCESS}

\title{
Increasing the perceived relevance of cervical screening in older women who do not plan to attend screening
}

\author{
Laura A V Marlow 도 , Mairead Ryan, Jo Waller
}

\begin{abstract}
- Additional material is published online only. To view please visit the journal online (http://dx.doi.org/10. 1136sextrans-2019-054120).
\end{abstract}

Department of Behavioural Science and Health, University College London, London, UK

\section{Correspondence to}

Dr Laura A V Marlow, Department of Behavioural Science and Health, University College London, London WC1E 6BT, UK; I.marlow@ucl.ac.uk

Received 7 May 2019 Revised 8 July 2019 Accepted 17 July 2019 Published Online First 8 August 2019

Check for updates

(C) Author(s) (or their employer(s)) 2020. Re-use permitted under CC BY. Published by BMJ.

To cite: Marlow LAV, Ryan M Waller J. Sex Transm Infect 2020;96:20-25.

\begin{abstract}
Objectives Uptake of cervical screening among women aged 50-64 years is declining. Not feeling at risk because of current sexual behaviour is a reason some older women give for not being screened. We hypothesised that explaining the long interval between acquiring human papillomavirus (HPV) and developing cervical cancer would increase the relevance of screening in older women.
\end{abstract}

Methods Women aged $50-64$ years $(n=597)$ who did not intend to go for screening were recruited through an online panel and randomised to one of three information conditions: cause only (basic information about HPV and cervical cancer), cause with basic timeline (also read a sentence describing the long interval between acquiring HPV and developing cervical cancer) and cause with explicit timeline (read the same as the timeline group alongside an explanation of what this means for older women). Perceived risk of cervical cancer, screening intention strength and understanding of HPV were assessed preinformation and postinformation exposure. Results Information condition was significantly associated with risk perceptions and intention strength postintervention $(F(2,593)=6.26, p=0.002$ and $F(2,593)=4.98, p=0.007$ respectively). Women in the cause with explicit timeline condition were more likely to increase their risk perceptions and intention strength compared with cause only (24\% vs $9 \%$ and $25 \%$ vs $13 \%$ for risk perceptions and intention, respectively). In the cause with explicit timeline group, women with 4-10 lifetime partners had higher odds of increasing their perceived risk and intention strength postintervention compared with those with $0-1$ partners $(O R=2.27,95 \%$ $\mathrm{Cl} 1.01$ to 5.12 and $\mathrm{OR}=3.20,95 \% \mathrm{Cl} 1.34$ to 7.67 , respectively).

Conclusions Providing a clear explanation that decouples women's perceived cervical cancer risk from their current sexual behaviour has the potential to increase perceived risk of cervical cancer and intentions to be screened among older women. Providing women with a clear cognitive representation of the aetiology of cervical cancer may be one approach to increasing screening uptake.

\section{INTRODUCTION}

Adequate cervical screening between 50 and 64 years is associated with lower risk of cervical cancer, ${ }^{1}$ yet a growing number of women in this age range are not attending screening. ${ }^{2}$ Recent work suggests that unlike younger women who are more likely to intend to go for screening but not get around to it, older women are more likely to have made an active decision not to be screened. ${ }^{3}$ Further exploration of health beliefs in the same sample suggests that women who decide not to be screened have lower cervical cancer risk perceptions. ${ }^{45}$ Older women are also less likely to believe that cervical screening reduces their risk of cancer ${ }^{6}$ and some studies suggest that perceived relevance of screening is lower in older women because of perceptions about their current sexual activity. ${ }^{278}$

Having many sexual partners is the most commonly mentioned risk factor when using unprompted questions about what causes cervical cancer, ${ }^{9}$ and older women are more likely to cite sexual activity and having multiple partners as causes of cervical cancer than younger women. ${ }^{6}$ The introduction of human papillomavirus (HPV) primary screening and associated shift in the focus of screening to look for an STI may increase awareness of this association. ${ }^{7}$ In a study where women were asked to read information about HPV, its sexually transmitted nature and its link with cervical cancer, perceived risk of cervical cancer increased among the youngest women ( $<25$ years) but decreased among the oldest women ( $>64$ years). ${ }^{10}$ Perceived risk did not change for women who were in the screening age range (25-64 years).

Evidence suggests that women over 50 years are less likely to have new sexual partners and more likely to be in long-term monogamous relationships, ${ }^{11}$ but progression from persistent HPV to cervical cancer takes an average of 12-15 years, so previous, rather than current, sexual behaviour is indicative of risk. ${ }^{12}$ A newly detected HPV infection in an older woman could result from an infection acquired many years ago, reflecting persistence or reactivation, rather than a new infection. ${ }^{13}$ Most information about cervical cancer now incorporates details of the causal role of HPV; however, a systematic review of studies exploring women's frequently asked questions about HPV suggested that many have a desire to understand the 'timeline' of progression from HPV to cervical cancer. ${ }^{14}$ In addition, Leventhal's common sense model of illness ${ }^{15}$ theorises that beliefs about causes and timeline, as well as consequences, control and symptoms are important in helping people develop a coherent cognitive representation of their illness. This 
provides a useful framework for considering aspects of HPV that should be communicated to women to help improve their understanding of HPV and its link with cervical cancer. ${ }^{16}$ For older women in particular, good integration of timeline and causal information would facilitate a more coherent understanding of their risk, by making it clear that previous sexual history is as important as current sexual behaviour. The present study tested the hypothesis that presenting information about the long timeline of progression from HPV to cervical cancer could increase perceived risk of cervical cancer and cervical screening intention strength among women aged 50-64 years.

\section{METHODS}

\section{Participants}

Participants were identified through an online panel maintained by Dynata Global UK ltd. Emails were sent to participants who were registered as being female and aged 50-64 years. The email asked participants to click a link, which directed them to an online survey (hosted by Survey Monkey). After reading the study information page and indicating consent to participate, women were asked to confirm their age, country of residence and their future screening intentions. Women were eligible for the study if they were 50-64 years old, living in Britain and responded that they would 'probably not' or 'definitely not' attend cervical screening the next time they were invited (ie, they were nonintenders). We estimated that 200 women in each condition would result in approximately $80 \%$ power to detect a difference of 0.22 in perceived risk of cervical cancer $(S D=0.8)$ with alpha $=0.05$. The expected effect size was based on a previous study exploring perceived risk of cervical cancer preinformation and postinformation about HPV. ${ }^{17}$ We therefore commissioned recruitment of 600 non-intenders. Recruitment emails were sent in waves until the target sample size had been reached.

\section{Procedure}

Eligible women completed baseline measures assessing perceived risk of cervical cancer, cervical screening intention strength and attitudes to screening. Participants were then randomised to read one of three pieces of text about HPV and cervical cancer. After reading the information, women were asked to complete three questions based on its content, as a comprehension check. If any of these were incorrect, they were returned to the information and asked to read it again. The comprehension check was repeated up to two times before letting a participant progress. Participants then completed the items on perceived risk, intention strength and attitudes to screening for a second time.

\section{Intervention}

The intervention was designed to improve knowledge about the timeline of HPV and cervical cancer, a gap in knowledge that has been identified in previous studies. ${ }^{14}$ This intervention focuses on the 'education' function of the Behaviour Change Wheel, ${ }^{18}$ and we hypothesised this would increase women's motivation to attend. Participants were randomised to one of three information conditions (see table 1): cause only (basic information about HPV and cervical cancer), cause with basic timeline (also read a sentence describing the long interval between acquiring HPV and developing cervical cancer) and cause with explicit timeline (read the same as the timeline group alongside an explanation of what this means for older women).

\section{Measures}

Outcomes: perceived risk of cervical cancer was assessed using a single item: 'How likely do you think you are to develop cervical cancer in the next 10 years?'. Cervical screening intention strength was assessed using the question: 'How likely is it that you will attend screening when next invited?'. Both outcome measures used a 7-point Likert scale (from very unlikely to very likely). A single item assessed self-rated understanding of HPV 'I understand how human papillomavirus (HPV) can cause cervical cancer' using a 7-point Likert scale (from strongly disagree to strongly agree).

Sociodemographic characteristics: age was collected using an open box at the beginning of the survey. At the end of the survey, participants were asked additional sociodemographic questions including ethnicity (17 categories - based on the 2011 census question), ${ }^{19}$ highest educational qualification (no formal qualifications, O-levels or General Certificate of Secondary Education (GCSE) or equivalent, A-levels, Ordinary National Certificate (ONC)/Business and Technology Education Council (BTEC)/National Vocational Qualification (NVQ), degree or higher, still studying and don't know) and marital status (single, married/cohabiting, separated, divorced and widowed). Participants were also asked if they had heard of HPV (yes, no and don't know).

Sexual history: women were asked three questions about their sexual history based on the National Survey of Sexual Attitudes and Lifestyles questionnaire (Natsal-3). ${ }^{20}$ These included whether they were currently in a sexual relationship (yes or no); number of previous partners $(0,1,2-3,4-5,6-10,11-20$ and $20+$ ) and length of time since last new partner (within the last 1 year, 5 years, 10 years, 20 years and over 20 years). All sexual history items included a 'prefer not to say' option.

Table 1 Information provided to women

Cause only information (control) ${ }^{*} \quad$ What affects my chances of getting cervical cancer?

Almost all cases of cervical cancer are caused by HPV infections. HPV can be passed on through any type of sexual activity with a man or women.

Women and men who have had more sexual partners are more likely to get HPV infections. However, HPV is so common that most people will have the virus at some point in their life.

HPV is found on the skin around the whole genital area and can spread through any type of sexual activity. This means that condoms do not protect you from getting an HPV infection.

Cause with basic timeline information Same information as the control information, followed by: HPV can take a long time to develop into cancer (10-30 years).

Cause with explicit timeline Same information as the control information, followed by:

information

Women aged 50-64 years should be aware that HPV can take a long time to develop into cancer (10-30years). This means that even if you have not been sexually active for a long time or have only had one partner for a long time, you could still be at risk of cervical cancer.

*This information is from the NHS cervical screening programme 'Helping you decide' leaflet.

HPV, human papillomavirus; NHS, National Health Service. 


\section{Analysis}

Primary analyses: we used analyses of covariance (ANCOVA) to establish if there were main effects for information condition (three levels: cause only, cause with basic timeline and cause with explicit timeline) on perceived risk of cervical cancer and cervical screening intention strength (adjusting for baseline scores). To explore the differences in more detail, change scores were calculated by subtracting preintervention scores from postintervention scores and reclassifying responses into binary outcomes for change in risk perception and change in intention $(1=$ increased; $0=$ decreased/no change). This allowed us to look at the proportion of women in each condition who increased their perceived risk and intention strength. Percentage change, $\chi^{2}$ (with $p$ value) and OR, with CI are reported. Sensitivity analyses were used to see if excluding participants who failed the comprehension check twice $(n=92)$ influenced the findings.

Secondary analyses: we initially planned (a priori) to explore associations between marital status/sexual history and change in intention in the intervention groups to see if these variables moderated any impact of the intervention. Since the cause with basic timeline intervention did not have any overall impact, we decided to look only at women in the cause with explicit timeline group $(n=216)$. We ran logistic regression models to explore bivariate associations between marital status and sexual history (current sexual relationship, number of lifetime partners and time since last new partner) and having increased perceived risk or screening intention strength (reference group $=$ those who decreased or did not change their risk/intention). ORs with CI are reported. We also explored whether the interventions improved self-rated understanding of HPV using ANCOVA (adjusting for baseline scores).

\section{RESULTS \\ Sample}

In total, 4215 eligible women aged 50-64 years were directed to the survey and consented to participate. Fifteen per cent of these women said they would probably not $(n=450)$ or definitely not $(\mathrm{n}=173)$ attend cervical screening when next invited and were included in the study (see online supplementary figure 1). Sample characteristics are reported in table 2. Most women were currently overdue for screening $(n=367)$ and $18 \%$ reported that they had never been screened $(n=105)$. Half of the women were married and over a third had degree level education (40\%). Most women reported that they were not currently in a sexual relationship (62\%) and very few reported having a new partner within the last 5 years (5\%), but $42 \%$ reported four or more lifetime sexual partners. Women were randomised to the three conditions as follows: cause only $(\mathrm{n}=183)$, cause with basic timeline $(\mathrm{n}=198)$ or cause with explicit timeline $(\mathrm{n}=216)$. There were no sociodemographic or sexual history differences between women in the three conditions and no differences in the number of times women read the information they were provided by group.

\section{Perceived risk and intention strength}

Information condition was significantly associated with risk perceptions $(\mathrm{F}(2,593)=6.26, \mathrm{p}=0.002 ;$ cause only $\bar{x}=1.72$, cause with basic timeline $\bar{x}=1.82$ and cause with explicit timeline $\bar{x}=1.98)$ and intention strength $(\mathrm{F}(2,593)=4.98$, $\mathrm{p}=0.007$; cause only $\bar{x}=2.15$, cause with basic timeline $\bar{x}$ $=2.16$ and cause with explicit timeline $\bar{x}=2.30$ ). In sensitivity analyses excluding women who failed the comprehension
Table 2 Sample characteristics $(n=597)$

\begin{tabular}{|c|c|c|}
\hline & $\mathbf{n}$ & $\%$ \\
\hline \multicolumn{3}{|l|}{ Age (years) } \\
\hline $50-54$ & 171 & 28.6 \\
\hline $55-59$ & 180 & 30.2 \\
\hline $60-64$ & 246 & 41.2 \\
\hline \multicolumn{3}{|l|}{ Education } \\
\hline No formal qualifications & 29 & 4.9 \\
\hline Any below degree & 312 & 52.3 \\
\hline Degree & 237 & 39.7 \\
\hline Other/still studying & 19 & 3.2 \\
\hline \multicolumn{3}{|l|}{ Ethnicity } \\
\hline White British & 551 & 92.3 \\
\hline Non-white British & 40 & 6.7 \\
\hline \multicolumn{3}{|l|}{ Marital status } \\
\hline Married or cohabiting & 314 & 52.6 \\
\hline Separated, divorced, widowed & 121 & 20.3 \\
\hline Single & 155 & 26.0 \\
\hline \multicolumn{3}{|l|}{ Heard of HPV } \\
\hline Yes & 433 & 72.5 \\
\hline No/don't know & 164 & 27.5 \\
\hline \multicolumn{3}{|l|}{ Currently in a sexual relationship } \\
\hline Yes & 197 & 33.0 \\
\hline No & 370 & 62.0 \\
\hline Prefer not to say & 30 & 5.0 \\
\hline \multicolumn{3}{|c|}{ Number of partners over the lifetime } \\
\hline None & 40 & 6.7 \\
\hline 1 & 135 & 22.6 \\
\hline $2-3$ & 123 & 20.6 \\
\hline $4-10$ & 158 & 26.5 \\
\hline$>10$ & 90 & 15.1 \\
\hline Prefer not to say & 50 & 8.4 \\
\hline \multicolumn{3}{|l|}{ Last new partner } \\
\hline Within the last 10 years & 105 & 17.6 \\
\hline Within the last 20 years & 99 & 16.6 \\
\hline 20 years or more & 332 & 55.6 \\
\hline Prefer not to say & 58 & 9.7 \\
\hline \multicolumn{3}{|l|}{ Screening status } \\
\hline Up to date & 125 & 20.9 \\
\hline Overdue & 367 & 61.5 \\
\hline Never had a test & 105 & 17.6 \\
\hline
\end{tabular}

Note: percentages that do not add up to $100 \%$ are due to missing data. HPV, human papillomavirus.

check, the means and SD were similar and differences remained significant.

Figure 1 shows the percentages of women whose perceived risk increased after reading the information provided. Women in the cause with explicit timeline condition were more likely to have an increase compared with those in the cause only condition: $24 \% \mathrm{v} 9 \%,\left(\chi^{2}(1)=16.47, \mathrm{p}<0.001 ; \mathrm{OR}=3.31,95 \%\right.$ CI 1.82 to 6.03$)$ and were also more likely to increase their intention strength: $25 \%$ versus $13 \%\left(\chi^{2}(1)=9.83, \mathrm{p}<0.001\right.$; $\mathrm{OR}=2.32$, 95\% CI 1.36 to 3.96$)$. The percentages of women with increases in perceived risk and intention strength in the cause with basic timeline condition were no different from the cause only condition ( $14 \%$ vs $9 \%: \chi^{2}(1)=2.27, p=0.132$; $\mathrm{OR}=1.65,95 \%$ CI 0.86 to 3.17 and $14 \%$ vs $13 \%: \chi^{2}(1)=0.20$, $\mathrm{p}=0.652 ; \mathrm{OR}=1.15,95 \%$ CI 0.63 to 2.07 , respectively). 


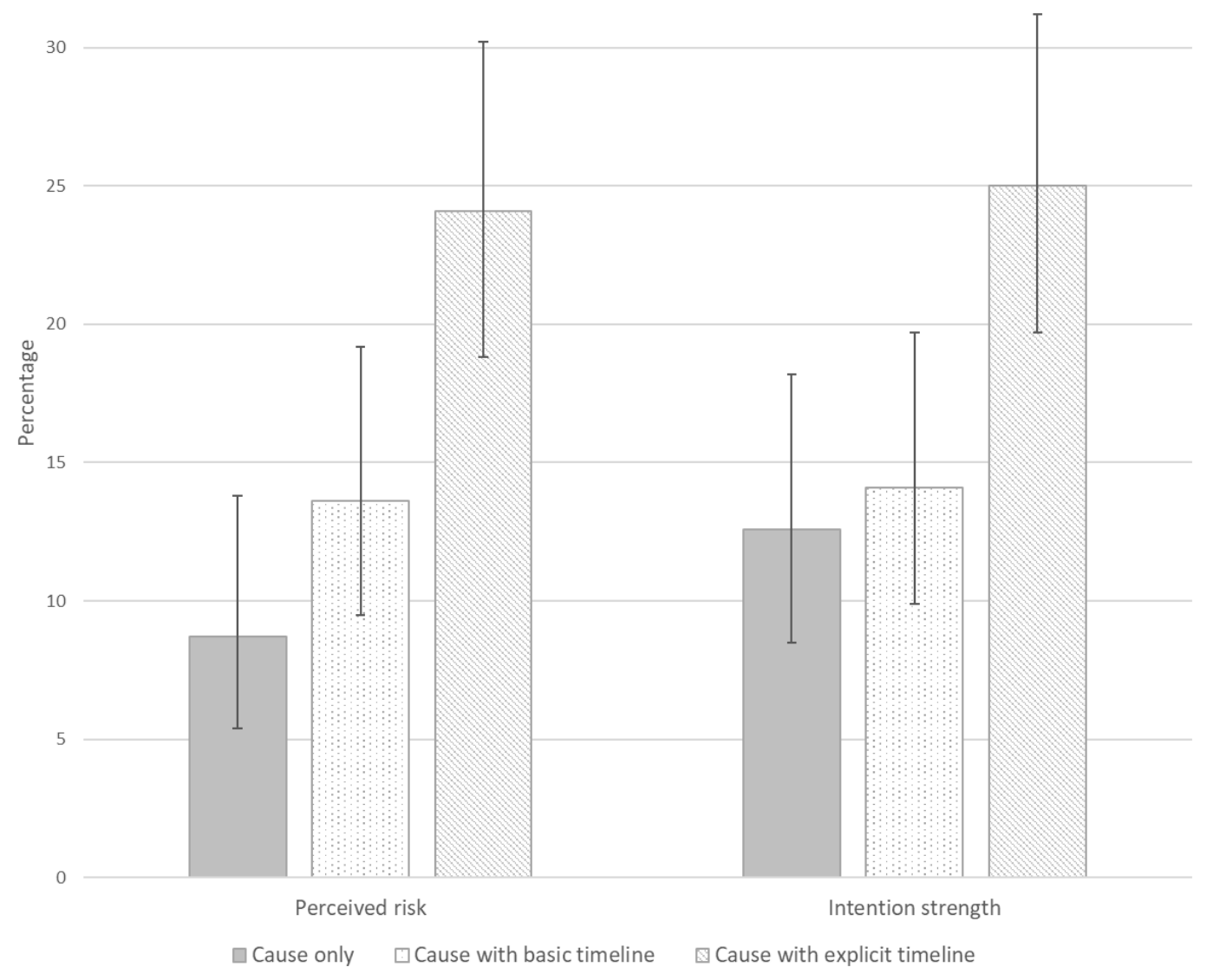

Figure 1 Percentage of women who increased their perceived risk and intention strength after reading the information provided (with $95 \% \mathrm{Cls}$ ).

\section{Marital status and sexual history}

Among women in the cause with explicit timeline condition $(\mathrm{n}=216)$, we explored whether marital status or sexual history were associated with increasing risk perceptions or intention strength after reading the information provided (see table 3). Women who had 4-10 lifetime partners were significantly more

Table 3 Unadjusted odds of increased risk/intention among women receiving cause with explicit timeline information ( $n=216)$

\begin{tabular}{|c|c|c|c|c|}
\hline & \multicolumn{2}{|c|}{ Increased risk perceptions } & \multicolumn{2}{|c|}{ Increased intention strength } \\
\hline & $\%$ & OR $(95 \% \mathrm{Cl})$ & $\%$ & OR $(95 \% \mathrm{Cl})$ \\
\hline \multicolumn{5}{|l|}{ Marital status } \\
\hline Married or cohabiting $(n=122)$ & 23.0 & 1.00 & 21.3 & 1.00 \\
\hline Separated, divorced, widowed $(n=43)$ & 25.6 & 1.15 (0.52 to 2.58$)$ & 34.9 & 1.98 (0.92 to 4.24$)$ \\
\hline Single $(n=48)$ & 27.1 & 1.25 (0.58 to 2.68$)$ & 25.0 & 1.23 (0.56 to 2.70$)$ \\
\hline \multicolumn{5}{|l|}{ Currently in a sexual relationship } \\
\hline No $(n=126)$ & 26.2 & 1.00 & 23.8 & 1.00 \\
\hline Yes $(n=78)$ & 23.1 & 0.85 (0.44 to 1.64$)$ & 25.6 & 1.10 (0.57 to 2.12 ) \\
\hline \multicolumn{5}{|l|}{ Number of partners over the lifetime } \\
\hline $0-1$ & 18.8 & 1.00 & 14.1 & 1.00 \\
\hline $2-3$ & 20.5 & 1.11 (0.43 to 2.29$)$ & 25.0 & 2.04 (0.76 to 5.43$)$ \\
\hline $4-10$ & 34.4 & $2.27(1.01 \text { to } 5.12)^{*}$ & 34.4 & $3.20(1.34 \text { to } 7.67)^{* *}$ \\
\hline$>10$ & 14.3 & $0.72(0.21$ to 2.47$)$ & 21.4 & $1.67(0.53$ to 5.24$)$ \\
\hline \multicolumn{5}{|l|}{ Last new partner } \\
\hline Within the last 10 years & 16.7 & 1.00 & 22.2 & 1.00 \\
\hline Within the last 20 years & 34.3 & 2.61 (0.85 to 8.00$)$ & 34.3 & 1.83 (0.64 to 5.22 ) \\
\hline 20 years or more & 22.0 & $1.41(0.53$ to 3.73$)$ & 22.0 & 1.05 (0.40 to 2.41$)$ \\
\hline
\end{tabular}

${ }^{*} \mathrm{P}<0.05,{ }^{* *} \mathrm{p}<.01$ 
likely to increase their perceived risk and intention strength postintervention, compared with those with $0-1$ sexual partner. There was no significant association for marital status, current sexual relationship status or length of time since last partner.

\section{Self-Rated understanding of HPV}

Preintervention, 54\% of women agreed that they understood how HPV can cause cervical cancer; postintervention this was $88 \%$. There were no between-group differences in self-rated understanding of HPV after reading the information provided: $\mathrm{F}(2,593)=0.79, \mathrm{p}>0.05$.

\section{DISCUSSION}

Reading brief information about the role of HPV in cervical cancer aetiology can improve women's confidence in their understanding of the causal pathway and is important for the move to HPV primary screening. For older women, explaining the long interval between acquiring HPV and developing cervical cancer can increase risk perceptions and intentions to be screened. However, providing a clear explanation for what the time lag means is important. Shifting risk perceptions and intentions to be screened is notoriously difficult, so the changes seen here are encouraging, especially because the women we included had all indicated that they probably or definitely would not go for screening in the future. In addition, the greater shifts observed among women whose sexual history placed them at greater risk was encouraging. National Health Service leaflets are currently being updated to take account of the move to HPV primary screening and development of an evidence-base to inform decisions about which information to include is important. Small changes to wording of written health information are low cost and easy to implement so even if effects are small, making changes to information materials based on evidence about which messages are beneficial is likely to be cost-effective.

Providing information about the timeline from HPV acquisition to cervical cancer development, in line with psychological theory, ${ }^{1516}$ can help women to form a more integrated cognitive representation of this process. This is important to make sure those who have decided not to be screened are making informed decisions. Developing targeted cervical screening information for older women may be the most helpful way to disseminate this message. Targeting materials to segments of the population can help to relieve the burden of sifting through unnecessary information and also address in greater detail factors that are relevant to that specific sub-group. ${ }^{21}$

\section{Strengths and limitations}

Participants were recruited through an online panel which means they do not necessarily represent the general population. This did however mean that we were able to selectively recruit women who did not intend to go for screening in the future, a group who are difficult to recruit through other routes. The proportion of women in our sample reporting more than 10 sexual partners was broadly similar to findings from Natsal $(15 \%$ in our sample and $12 \%$ in Natsal) but women reporting no sexual partners were overrepresented (as would be expected, as cervical screening uptake is low in women who have never been sexually active). Item nonresponse for the sexual history items was 5\%-10\%, which was slightly higher than in Natsal but lower than similar questions asked in the Health Survey for England 2010. ${ }^{22}$ The format of the study meant that women were asked to read a piece of information online and asked to reread this if they got the comprehension check wrong. While this allowed us to compare the impact of different information in a highly controlled way, it lacks the ecological validity that would come from testing the impact of this information when embedded in an information leaflet arriving alongside a screening invitation, which women may or may not read. The 'real-world' impact of such information would therefore need further support, but proof of principle research can be helpful in determining evidenced-based message content worthy of further testing in health materials. ${ }^{23}$

The mean overall change on the seven-point scale that was used to assess intention was from 2.1 to 2.3 , suggesting that across the sample the majority of women would still not intend to go for screening (responses of $<3$ represent a response of 'unlikely'). This is perhaps not surprising given that these women were nonintenders to begin with. A quarter of women reading the timeline information increased their intentions to be screened after the intervention, and while this is positive, it needs to be interpreted with caution. For some of these women, the intention shift was from selecting 'very unlikely' to 'unlikely'. While this is technically an increase in intention, it may not be considered a meaningful shift since intentions are still negative. In addition, given consistent evidence of an intention-behaviour gap in screening behaviour, further attenuation would be expected in the translation to behaviour. It is therefore likely that the intervention we have used would result in far fewer than a quarter of non-intenders getting screened.

The intervention developed here falls within the 'education' function of the Behaviour Change Wheel: increasing knowledge and understanding of HPV and cervical cancer. ${ }^{18}$ While information about the HPV-cervical cancer timeline may help increase motivation to be screened, interventions will need to be multifaceted in order to overcome other types of barriers that women report in relation to cervical screening (eg, emotional or physical discomfort or being too busy to attend). Making changes to the way in which cervical screening is communicated and offered will hopefully address barriers across all aspects of the behaviour system (capability, opportunity and motivation) and accumulate to have a significant impact on screening participation. Such changes may include incorporating effective cues to action alongside welldeveloped information. This could include prompts to plan participation, for example, using implementation intentions ${ }^{24}$ or system level changes (eg, offering preset appointments or using textmessage reminders). Though this study tested the impact of providing a written message about the relevance of screening for older women, the same message could become part of a face-to-face provider-led intervention for older women who do not wish to be screened. This may be particularly helpful in countries like the USA where postal invitations are less routine.

\section{Conclusion}

For older women, explaining the long interval between acquiring HPV and developing cervical cancer alongside an explicit explanation for what the time lag means for women their age has the potential to increase cervical screening intention strength in those with low screening intentions. Ideally, information for older women would provide this message in a targeted way. Considering further ways to improve the accuracy of women's cognitive representations of HPV and cervical cancer may help facilitate informed screening uptake.

Handling editor Dr Sevgi 0 Aral

Contributors LAVM and JW conceived the study. JW, MR and LAVM developed the measures. MR and LAVM managed the project. LAVM conducted the analyses and drafted the paper. All authors contributed to the final version of the manuscript. The 


\section{Key messages}

- Not feeling at risk of cervical cancer because of current sexual behaviour is one reason older women give for not being screened.

- A newly detected human papillomavirus (HPV) infection in an older woman could result from an infection acquired many years ago.

- Explaining the long interval between acquiring HPV and developing cervical cancer can increase the relevance of screening in older women.

corresponding author attests that all listed authors meet authorship criteria and that no others meeting the criteria have been omitted.

Funding This work was supported by a Cancer Research UK career development fellowship awarded to JW (grant reference: C7492/A17219).

Disclaimer The funder played no role in the study.

Competing interests None declared.

Patient consent for publication Not required.

Consent and ethical approval The study was approved by the UCL Research ethics committee (ref: 10353/004). All responses were collected anonymously.

Provenance and peer review Not commissioned; externally peer reviewed.

Data availability statement An anonymous dataset is available on request from the corresponding author: Dr Laura Marlow, I.marlow@ucl.ac.uk, OCRID: 00000003-1709-2397.

Open access This is an open access article distributed in accordance with the Creative Commons Attribution 4.0 Unported (CC BY 4.0) license, which permits others to copy, redistribute, remix, transform and build upon this work for any purpose, provided the original work is properly cited, a link to the licence is given, and indication of whether changes were made. See: https://creativecommons.org/ licenses/by/4.0/.

ORCID iD

Laura A V Marlow http://orcid.org/0000-0003-1709-2397

\section{REFERENCES}

1. Castañón A, Landy R, Cuzick J, et al. Cervical screening at age 50-64 years and the risk of cervical cancer at age 65 years and older: population-based case control study. PLoS Med 2014:11:e1001585.

2. Screening \& Immunisations team ND. Cervical Screening Programme: England, 201718,2018

3. Marlow LAV, Chorley AJ, Haddrell J, et al. Understanding the heterogeneity of cervical cancer screening non-participants: data from a national sample of British women. Eur J Cancer 2017;80:30-8.
4. Bennett KF, Waller J, Chorley AJ, et al. Barriers to cervical screening and interest in self-sampling among women who actively decline screening. J Med Screen 2018:969141318767471 (published Online First: 2018/04/14).

5. Marlow LAV, Ferrer RA, Chorley AJ, et al. Variation in health beliefs across different types of cervical screening non-participants. Prev Med 2018;111:204-9.

6. Waller J, McCaffery K, Wardle J. Beliefs about the risk factors for cervical cancer in a British population sample. Prev Med 2004;38:745-53.

7. Hope KA, Moss E, Redman CWE, et al. Psycho-social influences upon older women's decision to attend cervical screening: a review of current evidence. Prev Med 2017:101:60-6.

8. Waller J, Jackowska M, Marlow L, et al. Exploring age differences in reasons for nonattendance for cervical screening: a qualitative study. BJOG 2012;119:26-32.

9. Low EL, Simon AE, Lyons J, et al. What do British women know about cervical cancer symptoms and risk factors? Eur I Cancer 2012;48:3001-8.

10. Marlow LAV, Waller J, Wardle J. The impact of human papillomavirus information on perceived risk of cervical cancer. Cancer Epidemiol Biomark Prev 2009;18:373-6.

11. Mercer CH, Tanton C, Prah P, et al. Changes in sexual attitudes and lifestyles in Britain through the life course and over time: findings from the National surveys of sexual attitudes and lifestyles (Natsal). The Lancet 2013;382:1781-94.

12. Snijders PJF, Steenbergen RDM, Heideman DAM, et al. HPV-mediated cervical carcinogenesis: concepts and clinical implications. J Pathol 2006;208:152-64.

13. Gravitt PE, Rositch AF, Silver MI, et al. A cohort effect of the sexual revolution may be masking an increase in human papillomavirus detection at menopause in the United States. J Infect Dis 2013:207:272-80.

14. Hendry M, Pasterfield D, Lewis R, et al. Are women ready for the new cervical screening protocol in England? A systematic review and qualitative synthesis of views about human papillomavirus testing. Br J Cancer 2012;107:243-54.

15. Leventhal $H$, Meyer $D$, Nerenz $D$. The common sense representation of illness danger. In: Rachman S, ed. Contributions to medical psychology. New York: Pergamon Press, 1980: 7-30.

16. Marlow LAV, Wardle J, Grant N, et al. Human papillomavirus (HPV) information needs: a theoretical framework. J Fam Plann Reprod Health Care 2009;35:29-33.

17. Nadarzynski T, Waller J, Robb KA, et al. Perceived risk of cervical cancer among prescreening age women (18-24 years): the impact of information about cervical cancer risk factors and the causal role of HPV. Sex Transm Infect 2012:88:400-6.

18. Michie S, van Stralen MM, West R. The behaviour change wheel: a new method for characterising and designing behaviour change interventions. Implementation Sci 2011;6.

19. Statistics OfN. 2011 census questionnaire for England, 2011. Available: https://www. ons.gov.uk/census/2011census/howourcensusworks/howwetookthe2011census/ howwecollectedtheinformation/questionnairesdeliverycompletionandreturn

20. Erens B, Phelps A, Clifton S. National survey of sexual Attitutes and lifestyles 3 : technical report; 2013.

21. Kreuter MW, Strecher VJ, Glassman B. One size does not fit all: the case for tailoring print materials. Ann Behav Med 1999;21:276-83.

22. Prah $P$, Johnson AM, Nardone $A$, et al. Asking about sex in general health surveys: comparing the methods and findings of the 2010 health survey for England with those of the third national survey of sexual attitudes and lifestyles. PLoS One 2015;10:e0135203

23. Sheeran P, Klein WMP, Rothman AJ. Health behavior change: moving from observation to intervention. Annu Rev Psychol 2017;68:573-600.

24. Sheeran $P$, Orbell $S$. Using implementation intentions to increase attendance for cervical cancer screening. Health Psychol 2000;19:283-9. 